\title{
Investigation of Mechanical and Biological Properties of FDM 3D-Printed PLA Scaffolds With Radial Gradient Porosity for Tissue Engineering
}

Meltem Eryildiz ( $\nabla$ meltemeryildiz@beykent.edu.tr)

\section{Original Article}

Keywords: Gradient Porous Scaffold, Fused Deposition Modeling, Compressive Strength, Cell Viability

Posted Date: October 12th, 2021

DOl: https://doi.org/10.21203/rs.3.rs-944744/v1

License: (c) (i) This work is licensed under a Creative Commons Attribution 4.0 International License.

Read Full License 


\section{Abstract}

Scaffolds with gradient porosity have become very promising candidates for tissue engineering and bone implants because of the combination of better mechanical and biological requirements. In this paper, a novel approach is proposed to design bone scaffolds with gradient porosity similar to the structure of cortical and spongy (cancellous) bones. The radial gradient PLA scaffolds were designed to consist of three different regions with the gyroid infill and, fabricated by Fused deposition modeling (FDM). The biological and mechanical properties of the scaffolds were investigated in vitro. Dense scaffold (G100) had improved mechanical properties but showed decreased bone ingrowth properties. In addition, porous scaffolds provided enhanced biological properties but decreased in mechanical strength (G40-G20). The scaffolds with radial gradient porosity (G100-40-20) gave highest cell proliferation. Because, mean pore size is an important aspect of scaffolds for mimicking bone.

\section{Introduction}

Additive manufacturing (AM) is chosen in fabrication of scaffolds for bone tissue engineering because of its stability and high degree of reproducibility. Complex scaffold designs can be easily fabricated through AM. Fused deposition modeling (FDM) is an attractive 3D printing technique used to fabricate polymeric scaffolds [1, 2]. In FDM, a thermoplastic filament is guided through a heated nozzle, where it is heated to its melting point and then extruded onto a substrate layer by layer to form a scaffold [3].

Today, clinical medicine requires materials to restore and support the healing and regeneration of criticalsized bone defects. The bone tissue engineering enables the regenerating of critical-sized bone defects with the aid of a scaffold [1]. Scaffolds are the three dimensional (3D) biomaterials to which cells have been attached (in vitro or in vivo). Therefore, scaffold structure used for tissue engineering is of an essential role, it should be able to mimic the structure and biological function of tissues. In this regard, special biocompatible and biodegradable scaffolds are required. After degradation, they should be replaced by the natural support structure, therefore they should only be used as a temporary support for cell growth and cell adhesion. [1, 4]. Scaffolds are structures that are made up of porous materials that act as a substrate and allow the cells to grow. In order to allow the cells to attach, they need to have proper porosity and mechanical properties that mimic those of living tissue [5].

Usually a scaffold design uses of regular lattice arrangements having unit cells that repeat at regular intervals [6]. However, graded/gradient porous scaffolds are attractive candidates for bone graft due to their combination of biological and mechanical requirements [7]. It should be noted that bone has a functionally graded structure. This can be seen in the longitudinal cross-section of a long bone, where the bone at the ends looks like a sponge (cancellous or trabecular bone), while the bone in the middle is dense or low porosity (cortical bone) (Figure 1). Thus, based on the biomimetic method, a damaged bone structure can be better healed with a graded/gradient porous scaffold [8]. Therefore, functionally graded porous scaffolds can be used. They may result in the formation of new tissue that mimics the structure of natural tissue $[8,9]$. At the functionally graded porous scaffold, the large pore sized section will be put 
into bone to promote bone ingrowth, while the small pore sized section will allow cartilage to grow in. Both the bone ingrowth section and the cartilage ingrowth section can be made up of various scaffold. Dense porous structures provide excellent mechanical qualities, but poor bone ingrowth. Porous scaffold structures, on the other hand, have a high biological property but a low mechanical strength [8].

Porous scaffolds with homogeneous porosity have been researched previously in terms of pore size distribution, porosity distribution, composition, and mechanical characteristics. PLA scaffolds with different homogenous pore sizes and pore densities fabricated by Gragor et al [10]. Their mechanical and biological properties were examined. Cubo-Mateo et al. [11] fabricated scaffolds with $100 \%$ and $30 \%$ porosity and two different layer orientations. They compared the results in terms of mechanical properties. Cheng et al. [12] investigated scaffolds with two different porosities. it was stated that the scaffold with larger pore size accelerated the bone tissue development. Srinivas et al. [13] examined the mechanical properties of the scaffold with different porosity produced by the FDM method. It has been stated that the mechanical properties increased as the porosity decreased. However, as in these studies, the use of a homogenous porosity scaffold reduces the similarity to the structure of the bone, while graded/gradient porous scaffold allows increasing the bone formation significantly. Thus, it is important to produce graded/gradient porous scaffolds that provide improved biological and mechanical properties. However, graded/gradient porous scaffold studies are limited in the literature. Luca et al. [14] investigated linear gradient PCL scaffold, Sobral et al. [15] examined linear gradient $\varepsilon$-caprolactone scaffolds. Özeren and Altan [5] fabricated CoCr scaffolds wth hybrid porosity using the Selective Laser Melting (SLM) method. Surmeneva et al. [6] manufactured Ti-6Al-4V scaffolds with radial gradient porosity using electro beam melting (EBM) method. Liu et al. [7] studied Ti-6l-4V linear gradient scaffolds fabricated by SLM method. Wang et al. [9] examined bioceramic scaffolds with linear gradient porosity. All these investigations show that functionally graded/gradient porous scaffolds are promising for tissue engineering applications. When the literature studies are reviewed, it is seen that the functionally graded/gradient porous scaffolds were applied in the form of a linear gradient and mostly on metallic materials. Its application to PLA, which is one of the most widely used biodegradable synthetic polymer among scaffolds, was insufficient.

In this study, a novel PLA scaffold with gradient porosity that mimics the bimodal structure of cortical and cancellous bones are described. Instead of the grid infill pattern that researchers usually use, gyroid infill pattern, which is very similar to the bone structure, was used. The reason for choosing the gyroid infill pattern was to promote cell adhesion of the scaffold by increasing the surface area compared to grid infill pattern. Porosity, pore size, in vitro MTT cell proliferation and compressive strength of the scaffold with gradient porosity were studied. The main objective of this study is to fabricate a biomimetic PLA scaffold with gradient porosity to enhance its biological and mechanical properties.

\section{Materials And Methods}

\subsection{Materials}


Commercially available polylactic acid (PLA) filament (1.75 $\mathrm{mm}$ diameter) was used for the fabrication of scaffolds.

\subsection{Scaffold Fabrication}

Scaffolds were fabricated by fused deposition modeling (FDM) method. Creality ender $3 \mathrm{~d}$ pro was used which had $0.4 \mathrm{~mm}$ of nozzle diameter, $200^{\circ} \mathrm{C}$ of nozzle temperature and $0.2 \mathrm{~mm}$ of layer thickness. The scaffolds were designed in various porous geometries.

The CAD data of the scaffolds were saved in STL format. Then converted to G-code using slic3r software. Slic3r is an open source slicer software. The radial gradient PLA scaffolds were designed to consist of three different regions as given in Figure 2. Because the outer, the transition and inside surface of the scaffolds were designed to be $\% 100, \% 40$ and $\% 20$ dense, respectively. G100, G40 and G20 scaffolds were not designed as gradient PLA scaffolds; they were designed with a single porosity (homogenous) to clearly realize the effect of the gradient design.

In the experimental study, for compression tests, the scaffolds had a diameter of $20 \mathrm{~mm}$ and a height of $10 \mathrm{~mm}$. For MTT cell proliferation assays, the scaffolds had a diameter of $5 \mathrm{~mm}$ and a height of $5 \mathrm{~mm}$. Post-processings was not applied to the samples after fabrication. The fabricated radial gradient PLA scaffolds are shown in the Figure 3.

\subsection{Compression Test}

The compression test was done by using Instron 8872 uniaxial testing system with $25 \mathrm{kN}$ load cell with a test speed of $1 \mathrm{~mm} / \mathrm{min}$ at room temperature. The results presented were the average of three tests.

\subsection{MTT Cell Proliferation Assays}

Cell Proliferation Assays were performed using the methyl-thiazol-tetrazolium (MTT) technique after the scaffold samples had been cultured for 24 hours. In the experimental study, L929 cells were seeded a density of $10^{5}$ cells / $\mathrm{mL}$ on samples and cultured at $37{ }^{\circ} \mathrm{C}$ and $5 \% \mathrm{CO}_{2}$ in culture medium containing DMEM/F-12 10\% Fetal Bovine Serum. After 24 hours, the proliferation of cells on the scaffolds was examined. The culture medium was removed and $10 \mathrm{mg} / \mathrm{ml}$ concentration of MTT and serum-free medium was added to the medium and cultured for 4 hours in the above conditions. After 4 hours, the culture medium was removed, and the formazan crystals formed by enzyme activity in the living cells on the material were dissolved using acidic isopropanol and their absorbance at $570 \mathrm{~nm}$ were measured.

\subsection{Optical Microscopy}

The the geometrical properties of the fabricated scaffolds were examined using Zeiss Axio Zoom.V16 optical microscope. Then the optical microscope images of the scaffolds were used in Image $\mathrm{J}$ software for determining the geometrical properties of the scaffolds.

\subsection{Porosity measurement}


Porosity of the built scaffolds was calculated by weighing the scaffolds and using Eq. 1 [16]. The porosity of the three scaffold samples was averaged.

$$
\text { Porosity }(\%)=\frac{V_{t h} \rho-W_{m}}{V_{t h} \rho} \times 100
$$

Where $W_{m}$ was the scaffold's measured weight, $\rho$ was the PLA density, and $V_{t h}$ was the scaffold's volume.

The pore density $\left(\mathrm{N}_{\text {ceill }}\right)$ of the scaffolds was calculated by Eq. 2 [16],

$$
N_{\text {Cell }}=\left[\frac{n}{A}\right]^{3 / 2}
$$

Where $\mathrm{n}$ was the pores' number in the optical image and A is the optical image's area $\left(\mathrm{cm}^{2}\right)$.

\section{Results And Discussions}

\subsection{Geometrical properties of the scaffolds}

The geometrical properties of the fabricated scaffolds were examined by optical microscope shown in Figure 4. Furthermore, the pore density and porosity were determined. The results are given in Table 1.

Radial gradient scaffolds as bone implants mimic human bone because they have a diverse bone geometry that ranges from cortical bone to cancellous bone. As shown in Figure 4, G100-40-20, has three porosity gradient. Center zone have larger pores, aids the passage of living tissue and nutrition through the bone marrow, enhances vein generation. Surface zone mimic human cortical bone as exhibiting higher mechanical properties and strengthening the scaffold. Transition zone can be used for mimicking trabecular bone. In this way, radial gradient scaffold design may meet many properties of bones in terms of biological and mechanical properties. The thicknesses of these zones can be changed according to patient's demands.

\subsection{Mechanical properties of the scaffolds}

Tensile test results of scaffolds are displayed in Table 1 and Figure 5. According to results $6100-40-20$ scaffold showed enhanced mechanical properties over the G100-20 and G100-40. Due to its lower porosity, G100 conventional homogenous scaffold had highest mechanical properties. As can be seen from Figure 4, all structures exhibit a porosity that is interconnected. This interconnected porosity is very important factor for tissue ingrowth. It is indicated from Table 1 and Figure 5 that scaffold with radial gradient porosity exhibits improved strain, while the conventional homogenous scaffolds show brittle failure. 
The percentage of void area in a scaffold is known as porosity, and it is an important aspect in scaffold design and bone formation. More porous structure provide living tissue transition and nutrition transition, enhances vein generation because porous structures have larger specific surface area, while less porous zone may meet the mechanical strength of the scaffold when implanted. According to the compression test results, the mechanical properties of the scaffolds are reduced by porosity. Compressive stress increased with decreasing porosity. Larger pores can help to minimize the stress shielding of a porous scaffold by lowering the Young's modulus [8].

The mechanical properties of dense scaffolds (G100) are high but the bone ingrowth properties are poor. Porous materials, on the contrary, have a high biological performance but a low mechanical strength (G40-G20). Porous materials have a high pore surface area to bulk volume, allowing cells to attach and proliferate over a vast surface area. If the porous material is bioactive, the large pore surface area also suggest there is a significant bone-material interfacial bonding area [7-9].

\subsection{MTT Cell Proliferation Assays of the scaffolds}

The scaffolds' biocompatibility was tested over a 24-hour period. Cell proliferation assays are depicted in Figure 6 . The increase in absorbance is directly related to the increasing number of cells in all groups throughout the culture period.

Radial gradient scaffolds as bone implants mimic human bone because they have a diverse bone geometry that ranges from cortical bone to cancellous bone. Center zone have larger pores, aids not only cell growth, but also the passage of nutrients and metabolic waste. Surface zone mimic human cortical bone as exhibiting higher mechanical properties and strengthening the scaffold. Transition zone can be used for mimicking trabecular bone [9].

The homogeneous $\mathrm{G} 40$ and $\mathrm{G} 20$ scaffolds showed higher porosity then the graded porous scaffolds. The amount of void space in a scaffold is known as porosity, and it plays an important role in bio-scaffold design in vitro and bone formation in vivo [8,9]. According to the results, even though $G 20$ had the highest porosity, it did not have the highest cell proliferation. The G100-40-20 graded scaffold gave highest cell proliferation. Because, the mean pore size of scaffolds for tissue engineering is critical. If pores are too small, cells are unable to move towards the center of the construct, limiting nutrition diffusion and waste removal. Pores that are too large, on the other hand, reduce the available specific surface area, restricting cell attachment [17].

\section{Conclusions}

A novel PLA scaffold with a gradient porosity similar to the cortical and cancellous bone's bimodal structure was fabricated. Instead of the conventional grid infill pattern, gyroid infill pattern, which is very similar to the bone structure, was used because the gyroid infill pattern promotes cell adhesion of the scaffold by increasing the surface area. Porosity, pore size, MTT cell proliferation and compressive strength of the scaffold were examined in vitro. According to the results, the mechanical properties of 
dense scaffold (G100) was high but the bone ingrowth properties were poor. Porous materials, on the contrary, had a high biological performance but a low mechanical strength (G40-G20). Porous materials have a high pore surface area to bulk volume, allowing cells to attach and proliferate over a vast surface area. The scaffolds with radial gradient porosity (G100-40-20) gave highest cell proliferation. Because, the mean pore size of scaffolds for tissue engineering is a critical factor. For the further studies, different graded scaffold design and configurations can be made. Different layouts and shapes required for different purposes. For instance, a dense core-porous layer structure is appropriate for implants with high mechanical strength and bone ingrowth for stabilization, whereas a less porous layer-more porous core structure is appropriate for drug delivery systems.

\section{Declarations}

\section{Availability of data and materials}

Not applicable.

\section{Competing interests}

The authors declare that they have no competing interests.

\section{Funding}

Not applicable.

\section{Authors' contributions}

ME was in charge of the whole analyses and wrote the manuscript. The author read and approved the final manuscript.

\section{Acknowledgements}

Not applicable.

\section{Authors' information}

Assistant Prof. Dr. Meltem Eryildiz, born in 1987, works at Beykent University, Istanbul, Turkey. She obtained her Bachelor Degree, Master's degree and PhD degree in the Department of Mechanical Engineering at Yildiz Technical University, Turkey in 2009, 2014 and 2020, respectively. Her research interests mainly focus on polymer composites, polymer nano composites and manufacturing processes.

\section{References}

1. Szlązak, K., Jaroszewicz, J., Ostrowska, B., Jaroszewicz, T., Nabiałek, M., Szota, M., and Swieszkowski, W. (2016). Characterization of three-dimensional printed composite scaffolds 
prepared with different fabrication methods, Arch. Metall. Mater. 61(2), 645-650. doi: 10.1515/amm2016-0110

2. Roseti, L., Parisi, V., Petretta, M., Cavallo, C., Desando, G., Bartolotti, I., and Grigolo, B. (2017). Scaffolds for Bone Tissue Engineering: State of the art and new perspectives. Mater Sci Eng C, 78, 1246-1262. doi: 10.1016/j.msec.2017.05.017

3. Bracaglia, L.G., Smith, B.T., Watson, E., Arumugasaamy, N., Mikos, A.G., Fisher, J.P. (2017). 3D printing for the design and fabrication of polymer-based gradient scaffolds. Acta Biomater, 56, 3-13. doi: 10.1016/j.actbio.2017.03.030

4. Landers, R., Pfister, A., Hübner, U., John, H., Schmelzeisen, R., Mülhaupt, R. (2002). Fabrication of soft tissue engineering scaffolds by means of rapid prototyping techniques. J. Mater. Sci, 37, 3107-3116. doi:10.1023/A:1016189724389

5. Özeren, E., and Altan, M. (2020). Effect of structural hybrid design on mechanical and biological properties of CoCr scaffolds fabricated by selective laser melting. Rapid Prototyp. J, 26(4), 615-624. doi:10.1108/RPJ-07-2019-0186

6. Surmeneva, M.A., Surmenev, R.A., Chudinova, E.A., Koptioug, A., Tkachev, M.S., Gorodzha, S.N. and Rännar, L.E. (2017). Fabrication of multiple-layered gradient cellular metal scaffold via electron beam melting for segmental bone reconstruction. Mater. Des, 133, 195-204. doi:10.1016/j.matdes.2017.07.059

\section{Liu, F., Mao, Z., Zhang, P., Zhang, D.Z., Jiang, J. and Ma, Z. (2018). Functionally graded porous} scaffolds in multiple patterns: New design method, physical and mechanical properties. Mater. Des, 160, 849-860. doi:10.1016/j.matdes.2018.09.053

8. Miao, X., and Sun, D. (2010). Graded/Gradient Porous Biomaterials. Materials, 3, 26-47. doi:10.3390/ma3010026

9. Wang, Q., Wang, Q., and Wan, C. (2021). Preparation and evaluation of a biomimetic scaffold with porosity gradients in vitro. An. Acad. Bras. Cienc, 84(1). 9-16. doi: 10.1590/s000137652012000100003

10. Gregor, A., Filová, E., Novák, M., Kronek, J., Chlup, H., Buzgo, M., Blahnová, V., Lukášová, V., Bartoš, M., and Nečas, A. (2017). Designing of PLA scaffolds for bone tissue replacement fabricated by ordinary commercial 3D printer. J. Biol. Eng, 11(31), 1-21. doi: 10.1186/s13036-017-0074-3

11. Cubo-Mateo, N., and Rodríguez-Lorenzo, L.M. (2020). Design of Thermoplastic 3D-Printed Scaffolds for Bone Tissue Engineering: Influence of Parameters of "Hidden" Importance in the Physical Properties of Scaffolds. Polymers, 12(7), 2-14. doi: 10.3390/polym12071546

12. Cheng, M.Q., Wahafu, T.E.H.J., Jiang, G.F., Liu, W., Qiao, Y.Q., Peng, X.C., Cheng, T., Zhang, X.L., He, G., and Liu, X.Y. (2016). A novel open-porous magnesium scaffold with controllable microstructures and properties for bone regeneration. Sci Rep-Uk, 6, 1-14. doi: 10.1038/srep24134

13. Srinivasan, R., Ruban, W., Deepanraj, A., Bhuvanesh, R., and Bhuvanesh, T. (2020). Effect on infill density on mechanical properties of PETG part fabricated by fused deposition modelling. Mater. Today: Proc, 27(2), 1838-1842. doi: 10.1016/j.matpr.2020.03.797 
14. Luca, A., Ostrowska, B., Lorenzo-Moldero, I., Lepedda, A., Swieszkowski, W., Blitterswijk, C., and Moron, L. (2016). Gradients in pore size enhance the osteogenic differentiation of human mesenchymal stromal cells in three-dimensional scaffolds. Sci Rep, 6, 22898. doi:10.1038/srep22898

15. Sobral, J.M., Caridade, S.G., Sousa, R.A., Mano, J.F., and Reis, R.L. (2011). Three-dimensional plotted scaffolds with controlled pore size gradients: Effect of scaffold geometry on mechanical performance and cell seeding efficiency. Acta biomater, 7(3), 1009-1018. Doi: 10.1016/j.actbio.2010.11.003

16. Mi, H.Y., Salick, M.R., Jing, X., Jacques, B.R., Crone, W.C., Peng, X.F., and Turng, L.S. (2013). Characterization of thermoplastic polyurethane/polylactic acid (TPU/PLA) tissue engineering scaffolds fabricated by microcellular injection molding. Mater. Sci. Eng. C, 33(8), 4767-4776. doi: 10.1016/j.msec.2013.07.037

17. Murphy, C.M., and O'Brien, F.J. (2010). Understanding the effect of mean pore size on cell activity in collagen-glycosaminoglycan scaffolds. Cell Adh Migr, 4(3), 377-381. doi: 10.4161/cam.4.3.11747

\section{Tables}


Table 1. Compression test and porosity results of the 3D printed Radial Gradient PLA scaffolds

\begin{tabular}{|c|c|c|c|c|}
\hline Sample & $\begin{array}{c}\text { Porosity } \\
(\%)\end{array}$ & $\begin{array}{c}\text { Pore Density } \\
\left(\text { pore } / \mathbf{c m}^{3}\right)\end{array}$ & $\begin{array}{c}\text { Max. } \\
\text { Compressive } \\
\text { Stress (MPa) } \\
\end{array}$ & $\begin{array}{c}\text { Max. } \\
\text { Compressive } \\
\text { Strain (mm) } \\
\end{array}$ \\
\hline G100 & 42.83 & $6.29 \times 10^{-6}$ & 26.63 & 1.484 \\
\hline G40 & 63.92 & $3.69 \times 10^{-7}$ & 9.43 & 0.615 \\
\hline G20 & 73.01 & $4.53 \times 10^{-8}$ & 6.46 & 0.606 \\
\hline $\begin{array}{l}\text { G100- } \\
40-20\end{array}$ & 54.15 & $9.31 \times 10^{-7}$ & 19.75 & 1.47 \\
\hline $\begin{array}{c}\text { G100- } \\
20\end{array}$ & 59.03 & $5.18 \times 10^{-7}$ & 12.595 & 0.706 \\
\hline $\begin{array}{c}\text { G100- } \\
40\end{array}$ & 55.33 & $7.86 \times 10^{-7}$ & 14.048 & 0.902 \\
\hline
\end{tabular}

Figures 


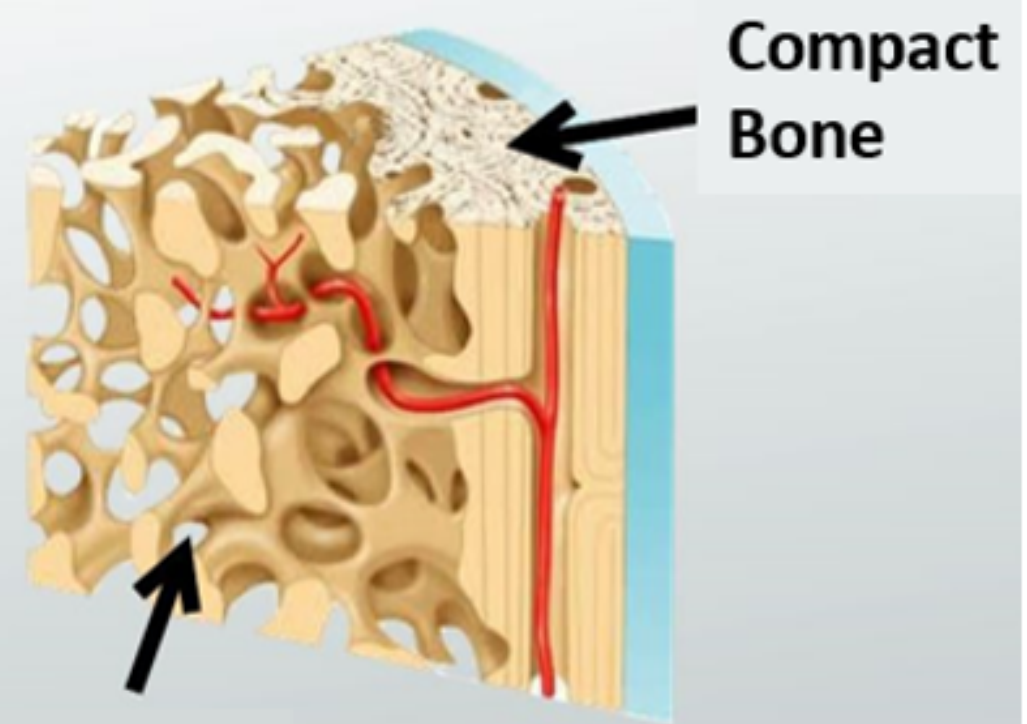

Spongy

Bone

Figure 1

Illustration of the bone structure, the outside cortical bone is compact bone, the inside of the bone contains spongy bone 


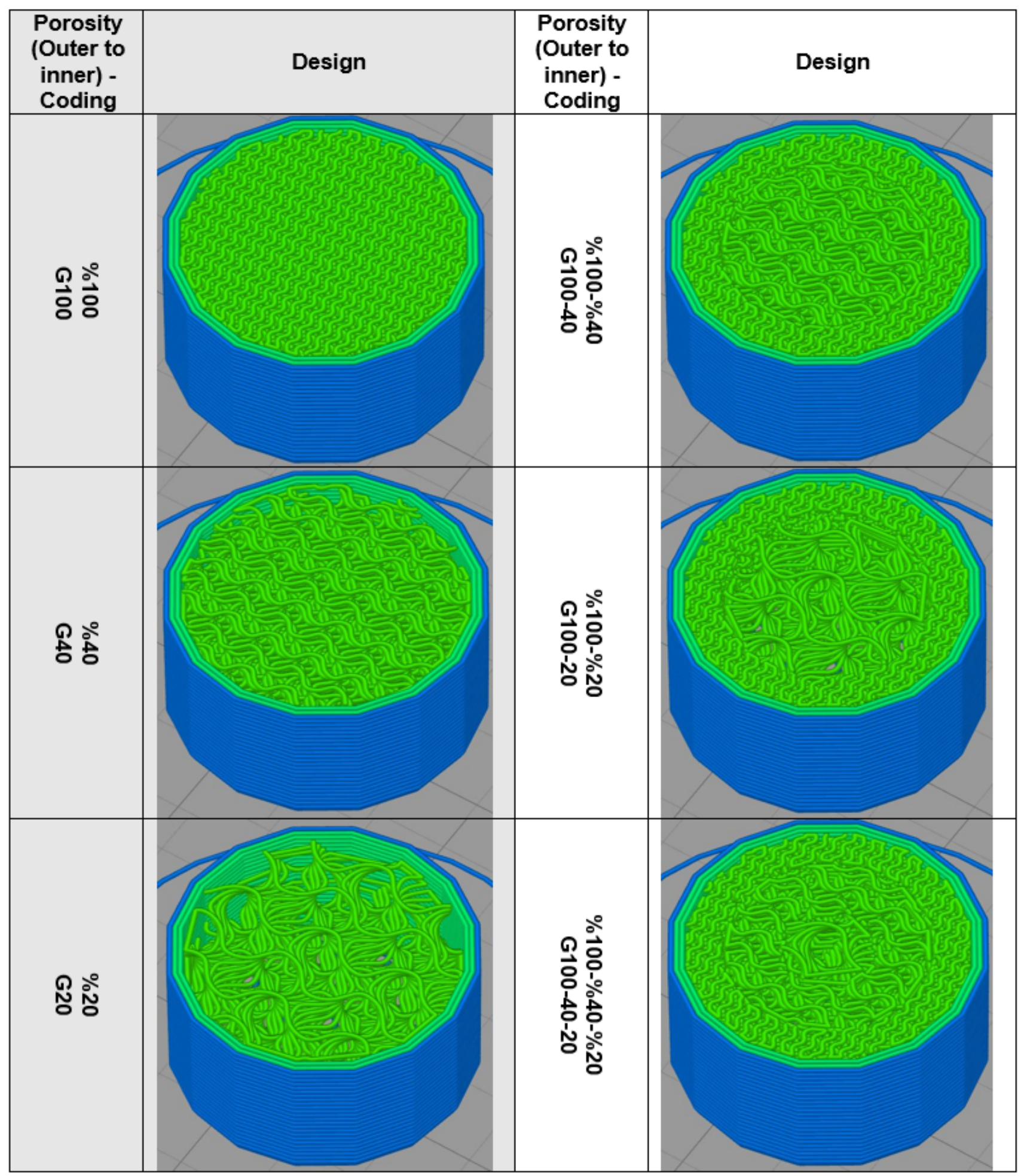

Figure 2

CAD images of the radial gradient PLA scaffolds 


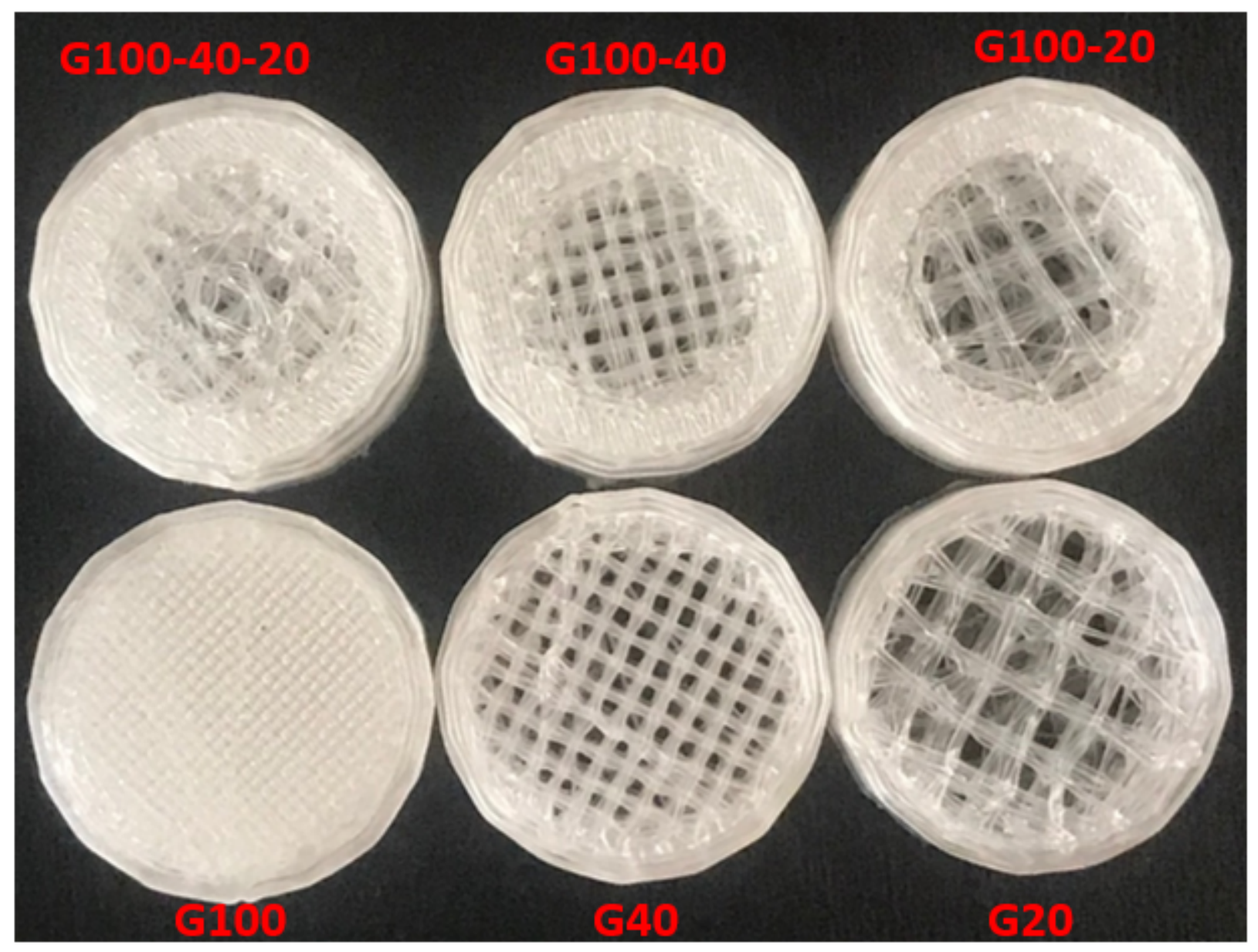

Figure 3

3D printed Radial Gradient PLA scaffolds 

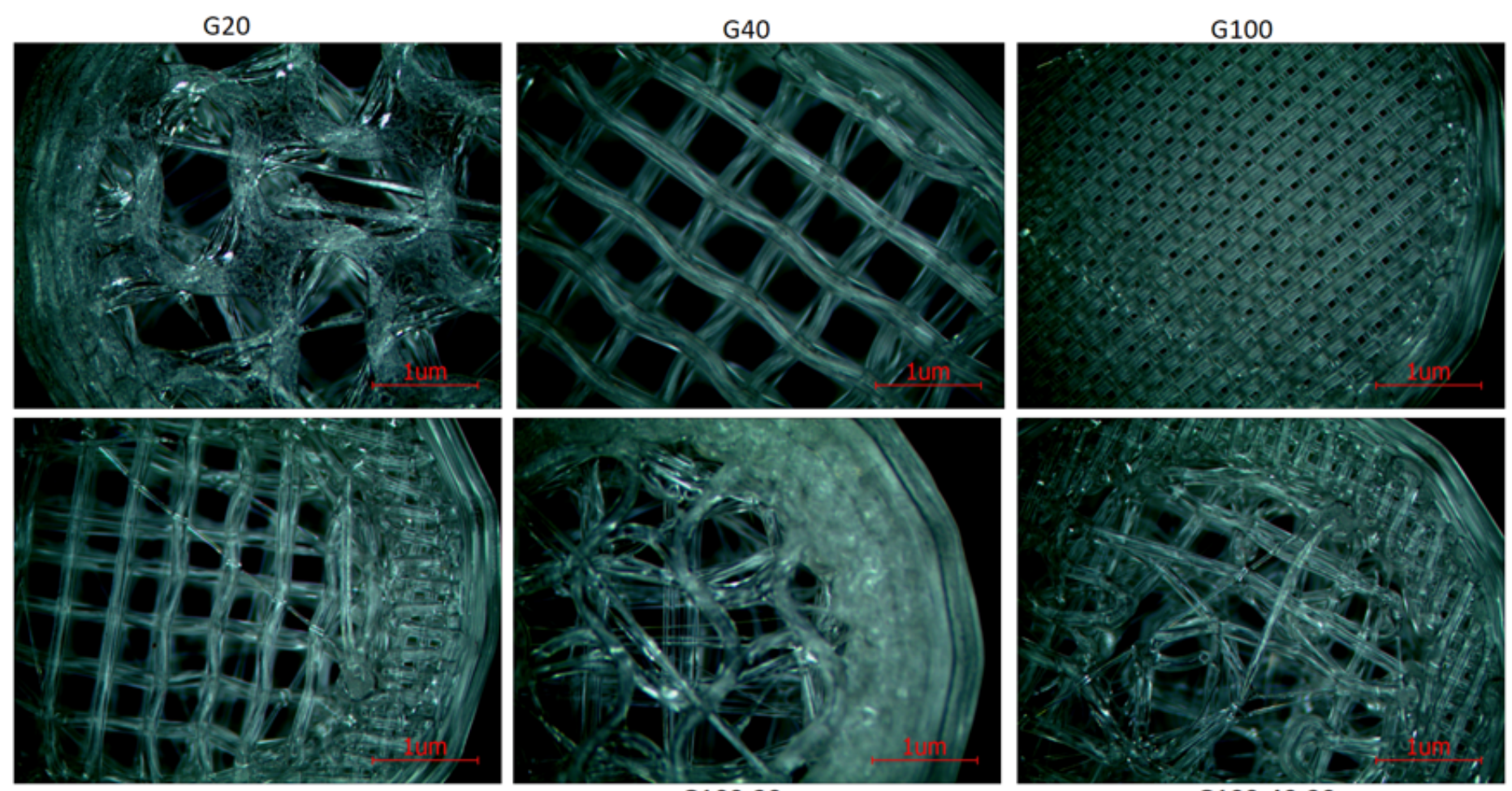

G100-40

G100-20

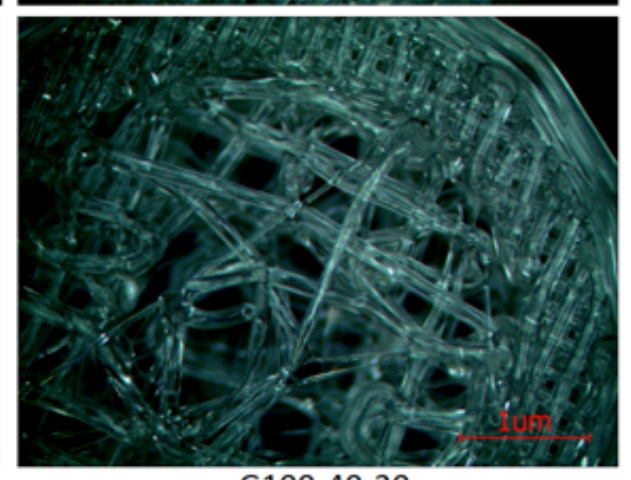

G100-40-20

Figure 4

Optical images of the scaffolds

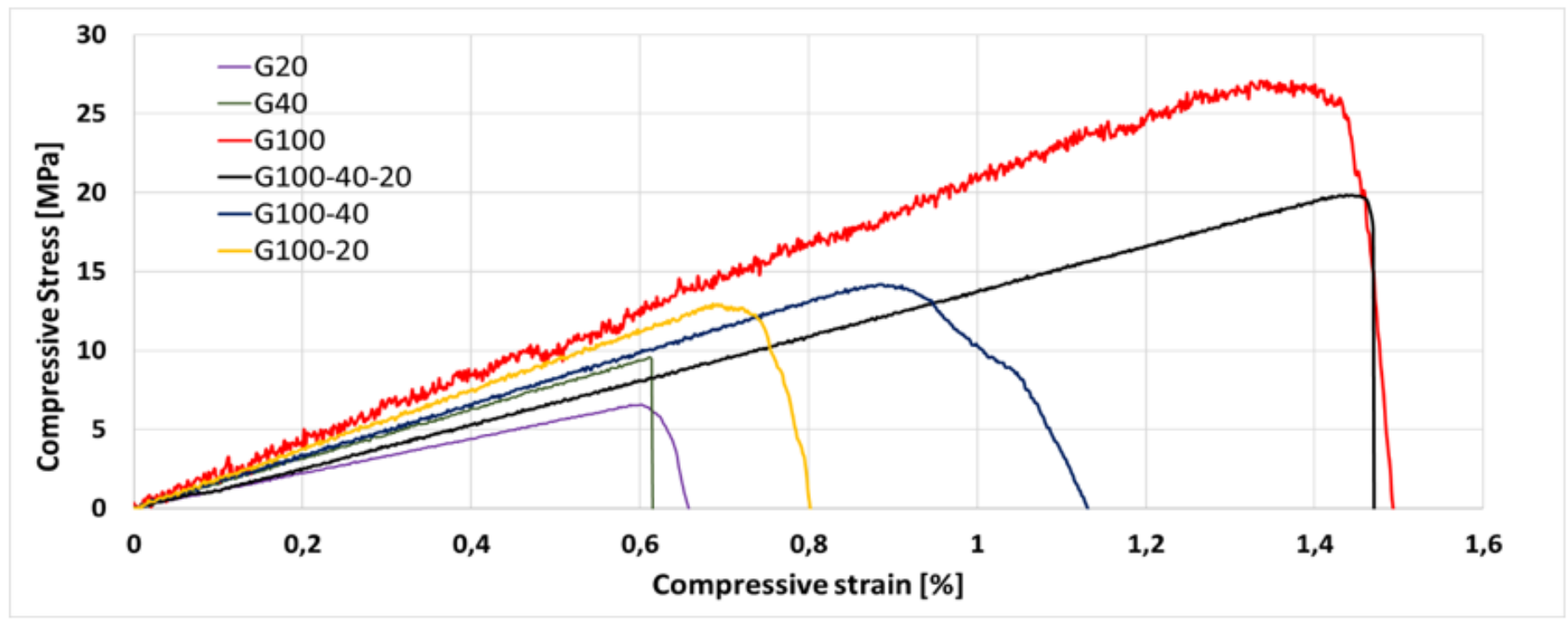

Figure 5

Stress-strain curve of the 3D printed PLA scaffolds 


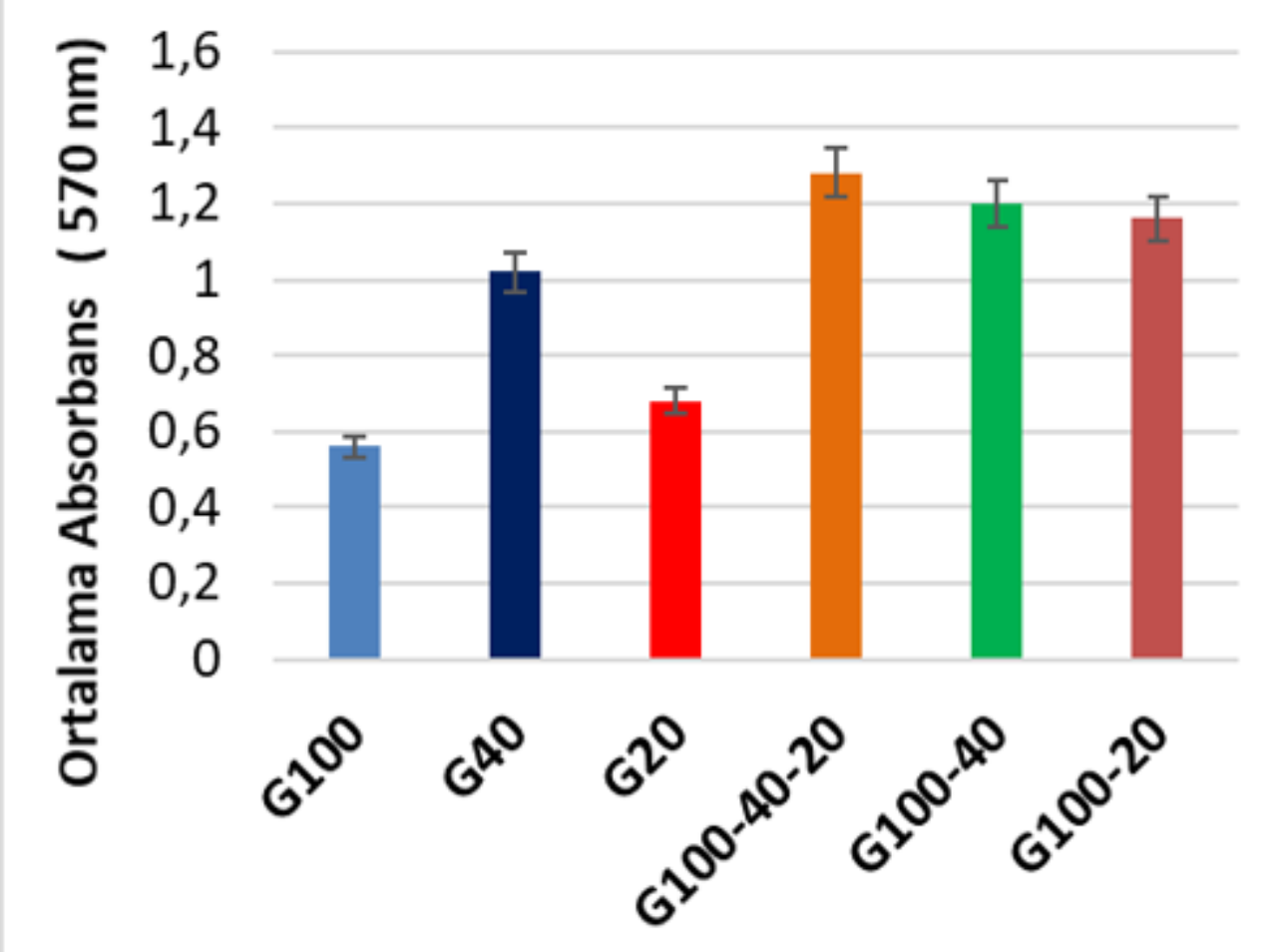

Figure 6

MTT Cell Proliferation Assays of L929 cells Seeded on a) G100, b) G40, c) G20, d) G100-40-20, e) G10040, f) G100-20 